\title{
Representações Sociais da Velhice entre Idosos que Participam de Grupos de Convivência
}

Social representation of the old age among elderly people who take part in groups of living together

Ludgleydson Fernandes de Araújo, Maria da Penha de Lima Coutinho \& Virgínia Ângela Menezes de Lucena e Carvalho Universidade Federal da Paraíba.

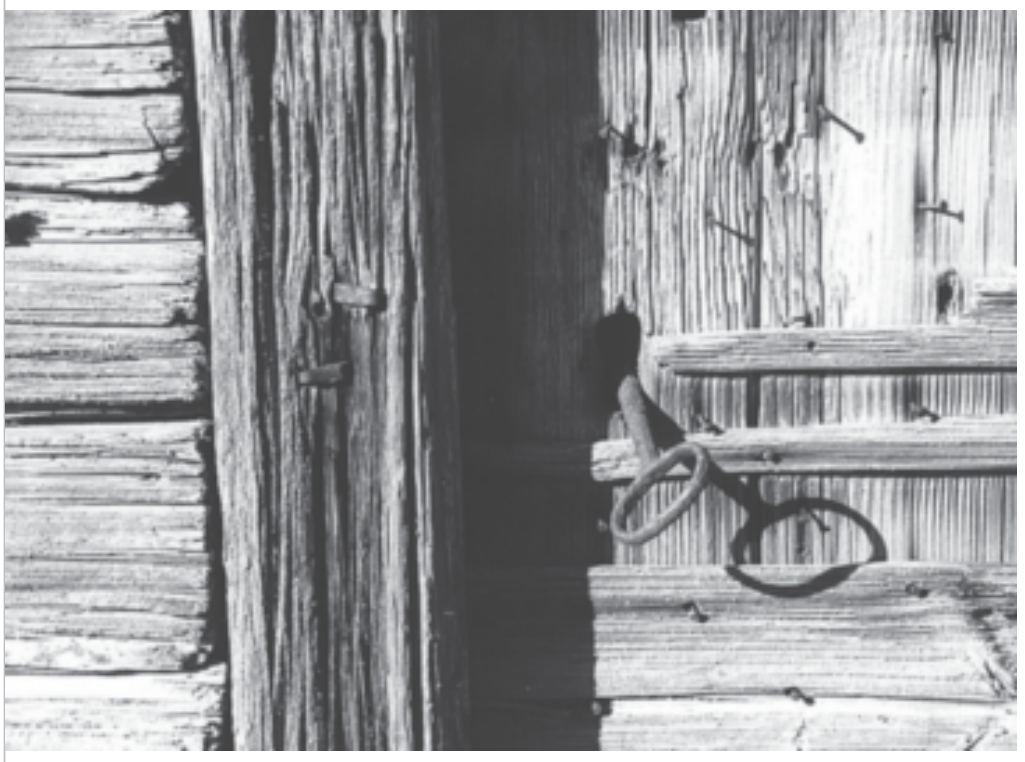




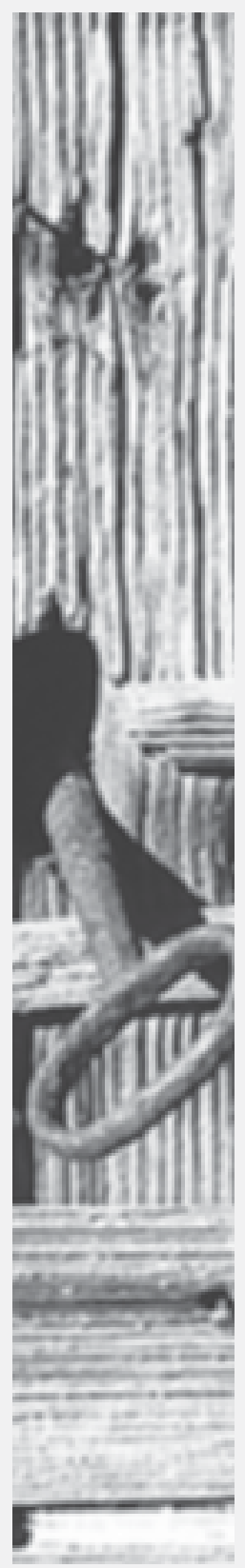

Resumo: O número de idosos brasileiros corresponde a 9,6\% da população total, o que equivale a mais de 15 milhões de idosos, segundo dados da Pesquisa Nacional por Amostra de Domicílios -PNAD (2003). Tendo como pressuposto tais dados oficiais, este trabalho objetiva identificar as representações sociais da velhice entre idosos de grupos de convivência (GC). Participaram 100 idosos, de ambos os sexos (90\% feminina e 10\% masculina), com média de idade de 65 anos, de dois GC - Juventude Prateada e Renascer, localizados na cidade de João Pessoa-PB. Utilizou-se o Teste de Associação Livre de Palavras, com os estímulos: velhice-grupos da terceira idade-família, realizadas em situação coletiva e de forma individual. Posteriormente, foi processado no software Tri-Deux-Mots, através de análise fatorial de correspondência. Verificaram-se, predominantemente, não só as representações negativas acerca da velhice como também uma associação entre velhice-doença. Concluiu-se pela importância dos grupos de convivência, nos quais as práticas sociais desenvolvidas contribuem para que os idosos exerçam seu papel de cidadãos.

Palavras-chave: velhice, grupos da terceira idade, representações sociais.

Abstract: The number of Brazilian elderly people corrresponds to 9,6\% of the total population, which refers to 15 million of elderly people according to the National Research by Number of Houses (PNAD-2003). Based on official data, this work has got the objective of identifying the social representations among old age groups of living together (GC). One hundred (100) elderly people took part, both sexes (90\% female and 10\% male), 65 year-old-average, selected amid two groups of living together, "Juventude Prateada" e "Renascer", situated in João Pessoa /PB. The Test of Free Association of Words was used with the stimulus: old age - the third age group - family, carried out individually and into the groups. It was processed in the software Tri-Deux-Mots as a means of factorial analysis of matching. It was verified a negative representantion about old age, as well as an association between old age - disease. It was concluded that the importance of groups living together lies in the developed social practices that help the elderly people to become aware of their role as citizens.

Key-words: old age, groups of living together, social representations. 
As diversas áreas do conhecimento vêm dando ênfase, em suas pautas de investigação e intervenção, à velhice e ao processo de envelhecimento bem como disponibilizando aparatos técnico-científicos para a melhoria das condições de vida dessa população, cujo crescimento gira em torno de 11 milhões a cada ano.

Um dos desafios enfrentados pela Psicologia do Envelhecimento, a priori, foi conciliar os conceitos de desenvolvimento e envelhecimento, tradicionalmente tratados como antagônicos, tanto pelos cientistas quanto pela sociedade civil e a família, tendo em vista que se considerava a velhice um período em que não havia desenvolvimento. Essa questão poderia ser amenizada com a ajuda da sociedade se esta providenciasse maior focalização em torno da longevidade, da saúde física e da adequação do ambiente às peculiaridades da velhice.

A Psicologia Social, particularmente nas últimas décadas, tem desenvolvido microteorias contemplando a velhice, de modo que tem contribuído, ao lado da Psicologia da Personalidade, para o entendimento dos diversos fatores intrínsecos ao processo de envelhecimento, possibilitando, com isso, intervenções psicossociais que propiciem melhores condições de vida ao idoso (Neri, 2002).

Nesse direcionamento, a presente investigação objetiva apreender as representações sociais da velhice entre idosos de grupos de convivências, tendo em vista o aumento significativo da população brasileira nessa faixa etária e, sobretudo, visando a contribuir para melhor compreensão e elucidação dos aspectos psicossociais sob o prisma do aporte teórico das representações sociais.

Inserem-se, assim, os grupos de convivência, no centro desta investigação, que propicia formas de aponderamento de cidadania para o cotidiano de seus participantes através de uma reflexão do seu entorno sociocultural e suscita mecanismos individuais e coletivos para ações de intervenção na velhice. Esses grupos foram idealizados com objetivos, atividades e propostas diferenciadas, com espaços para o lazer, a sociabilidade, a cultura e a construção de uma consciência de cidadania (Costa \& Campos, 2003).

É importante pontuar a questão do envelhecimento populacional não como uma preocupação no que os idosos representam para os fundos de pensão, serviços de saúde ou aumento de previdenciários, mas como a percepção, pela sociedade, de que são indivíduos pertencentes à fase do desenvolvimento humano em que podem ser empreendidas várias potencialidades concernentes à velhice (como a experiência, a responsabilidade, a assertividade, dentre outros) como também à inserção social do idoso no sentido de levá-lo a exercer o seu papel de um agente ativo que atua de forma dinâmica na estruturação da sociedade, tirando-Ihe o estereótipo negativo de que é incapaz e inútil (Araújo, 2004; Araújo \& Carvalho, 2004).

De acordo com PNAD - Pesquisa Nacional por Amostragem de Domicílios (2003), a população a partir de 60 anos ou mais representa 9,6\% da população total. O aumento no número de idosos na população brasileira é algo presente nas projeções demográficas, isso devido, sobretudo, aos avanços sócio-sanitários e ao aumento da longevidade.

Houve um aumento de cerca de 4 milhões de pessoas velhas na população total brasileira. Não obstante, um fato merece destaque acerca do crescimento de gerontes em escala progressiva no Brasil: como em todos os países, ele é devido à diminuição da taxa de natalidade e ao aumento da 
longevidade. Tendo por base projeções para o futuro, os dados apontam que, em 2020, uma em cada treze pessoas estará com 65 anos ou mais, algo em torno de 16.224.000 pessoas, significando que, de cada 100 brasileiros em idade laboral, existe, teoricamente, a responsabilidade por 11 idosos (Berquó, 1998).

De acordo com Moreira (2002), as modificações estruturais na composição etária brasileira são de natureza tal que, segundo se deduz das estimativas da ONU (Organização das Nações Unidas), no espaço de 100 anos entre 1950 e 2050, a proporção da população acima de 65 anos, inicialmente iior a 3\%, atingirá $18 \%$ ao final do período. Com isso, haverá também uma queda no contingente de pessoas menores de 15 anos que, em 1950 , representavam $41,6 \%$ e $28,8 \%$ em 2000, devendo chegar a algo em torno de apenas 19,9\% em 2050.

Tendo por base países da Europa (França, Inglaterra, Suécia, Alemanha, Suíça, dentre outros), nos quais se presenciam melhores condições de vida se comparados a países em desenvolvimento como o Brasil, o aumento da população idosa em nosso país já chega ao patamar dos $23 \%$ da população total. Isso, provavelmente, se deve ao rigoroso programa de controle de natalidade ao qual foram submetidos, com o conseqüente crescimento do número de pessoas velhas em sua população, tendo em vista também a expectativa de vida nesses países, que ultrapassa os 80 anos (Beltrão \& Camarano, 2002).

Em primeiro lugar no número de idosos, aparece a Itália, com $23 \%$ de sua população total, seguida do Japão, com $22 \%$, da Alemanha, com 21\%, da França, com 19\%, e do Uruguai, com $16 \%$. É válido salientar a predominância dos países ditos desenvolvidos nos primeiros lugares, tendo em vista as eficientes intervenções nos diversos setores da sociedade de modo a permitir uma considerável qualidade de vida.

Na América Latina, quem ocupa o primeiro lugar é o Uruguai (16\% população geronte), seguido da Argentina, com 13,2\%, de Cuba, com $13 \%$, do Chile, com $10 \%$, e do Brasil, com 9,6\%; faz-se necessário argumentar que este último ocupa, em nível mundial, o $13^{\circ}$ lugar, ao passo que, no continente latinoamericano, é o quinto país em número de idosos em sua população total.

Os dados mencionados acima confirmam a necessidade do desenvolvimento de mais pesquisas que venham contribuir para melhor compreensão e elucidação dos aspectos biopsicossociais e culturais, principalmente sob o prisma do aporte teórico das representações sociais. Essa teoria permite conhecer as práticas sociais e comunicações dos atores envolvidos na pesquisa (neste estudo, os idosos são participantes de grupos de convivência, como Juventude Prateada e Renascer) e como eles elaboram e compartilham desses conhecimentos, utilizando-os como referência nas comunicações inter e intragrupos e nos modelos de orientações comportamentais, afetivas e avaliativas no contexto social no qual se encontram inseridos.

A história das representações sociais (RS) insere-se na inter-relação entre atores sociais, o fenômeno e o contexto que os rodeia. Dessa forma, as representações sociais são constituídas por processos sociocognitivos nas interações sociais, o que significa dizer que elas têm implicações na vida cotidiana e que a comunicação e os comportamentos adotados por um grupo de indivíduos acerca de um objeto, neste estudo (representações sociais da velhice), são resultantes do modo como os atores sociais representam socialmente esse objeto e do significado que este adquire em suas vidas. 
Segundo Coutinho (2001), todos os fenômenos que emergem do contexto social são investidos simbolicamente, ou seja, recebem nomes e significados que os avaliam, explicam e Ihes dão sentido. Assim, a representação social da velhice, que faz parte do cotidiano social, recebe significados desde os mais longínquos tempos, fazendo parte dos aspectos socioculturais e históricos dos idosos de grupos de convivência. Esses significados, à medida que circulam, transformam-se e assumem formas diferentes de acordo com os modelos vigentes em uma determinada época e formação social.

Sabe-se, ainda, que esses significados são resultantes da interação entre o senso comum e o conhecimento erudito (científico), na qual existe uma relação de influência mútua e permanente entre esses dois universos, resultando numa diversidade de significados que circulam através dos meios de comunicação formais e informais, assimilados e reelaborados socialmente. Para conviver com essas implicações, os indivíduos constroem representações que Ihes auxiliam na atribuição de sentido para orientar seus comportamentos no decorrer da experiência com a referida problemática.

Para Doise (1990), a utilização da teoria das representações sociais é bastante útil à medida que se lida com um marco conceitual que envolve tanto o nível intrapessoal de análise quanto o interpessoal e o intergrupal; dessa forma, é possível partir das representações pessoais de objetos sociais para um exame das cognições no nível grupal, que permitem ao pesquisador a apreensão dos aspectos compartilhados de uma representação.

Essa visão coletiva em que a representação social é vista como um processo público de criação, elaboração, difusão e mudança do conhecimento compartilhado no discurso cotidiano dos grupos sociais (Doise, 1990;
Jodelet, 1989, 2001; Moscovici, 1984, 1988, 2003; Wagner \& Elejabameta,1994) é que será utilizada no desenvolvimento deste estudo, que vê a "representação social compreendida como a elaboração de um objeto social pela comunidade com o propósito de conduzir-se e comunicar-se" (Moscovici, 1984, p. 251).

Para Moscovici (1978), o objeto, seja ele humano, social, material ou uma idéia, será apreendido através da comunicação. Os elementos da realidade, os conceitos, as teorias e as práticas são submetidos a uma reconstrução a partir das informações colhidas e da bagagem histórica (social e pessoal) do sujeito. Assim sendo, as representações sociais tomam o objeto insignificante e tratam de explicar as características do pensamento social, diferenciando-o do pensamento individual.

Ainda segundo o pensamento de Moscovici (2003), toda representação surge da necessidade de transformar o que é estranho, o que não é compreendido, em algo familiar; essa seria uma das funções principais da representação "domar o desconhecido". Em geral, os grupos produzem representações, também como uma forma de filtração da informação que provém do ambiente, com a finalidade de amoldar o comportamento individual. É um tipo de manipulação do processo do pensamento e da estrutura da realidade.

O processo de construção de representações sociais da velhice processa-se nas trocas de conhecimentos populares e científicos, através de experiências grupais e sociais que se repetem ao longo da vivência dos indivíduos. Pesquisar as RS da velhice implica fazer uma leitura não só dos aportes teóricos normativos e científicos mas também do conhecimento cotidiano (senso comum) elaborado e compartilhado pelo grupo de pertença (Grupo Juventude Prateada e Renascer), procurando 
perceber como essas representações emergem, as relações que estabelecem entre si e em que medida uma determina a outra. As representações sociais da velhice têm implicações na vida cotidiana, à medida que os comportamentos adotados por um indivíduo ou grupo de indivíduos acometidos da prática desta são resultantes do modo como eles representam socialmente essa prática e do significado pessoal que esta adquire em suas vidas (Araújo \& Carvalho, 2005). Acredita-se que o estudo das representações sociais da velhice poderá contribuir para melhor compreensão desta e dos significados com os quais os indivíduos estabelecem relações com uma velhice bemsucedida.

Pode-se dizer que, apesar dos componentes cognitivos inerentes às representações, no que tange ao processamento e acomodação dos fenômenos re-apresentados, ou seja, apresentado outra vez de acordo com a interpretação do ator social, cujos valores, crenças, sentimentos, estereótipos estão intrínsecos, esse fenômeno não é só de base cognitiva, mas também social, histórica e cultural, nos quais se forma a representação. Assim, o presente estudo objetivou analisar e comparar as representações sociais dos idosos participantes de grupos de convivência acerca da velhice bem como identificar as representações sociais dos idosos em relação aos aspectos físico-orgânicos e psicossociais do envelhecimento humano.

\section{Método}

\section{Participantes}

A amostra foi não-probabilística, intencional e acidental, constituída de 100 idosos de ambos os sexos (90\% feminino e 10\% masculino), participantes dos grupos de convivência Juventude Prateada (50), mantido pela ABCMI (Associação Brasileira de Clubes da Melhor Idade), tendo caráter apenas de lazer e entretenimento, e do Grupo Renascer (50), que realiza suas atividades no SESC (Serviço Social do Comércio); este último desenvolve, além de atividades de lazer, atividades de promoção e prevenção à saúde do idoso, ambos localizados na cidade de João Pessoa-PB. Para participar da amostra, os idosos precisavam preencher alguns prérequisitos, como: ser assíduo aos grupos de convivência, ter idade igual ou superior a 60 anos (critério utilizado pela ONU em países em desenvolvimento como o Brasil) e desejar participar da pesquisa de forma anônima e voluntária.

\section{Instrumento}

Utilizou-se, como instrumento para coleta dos dados da pesquisa, a técnica de Associação Livre de Palavras. Essa é uma técnica bastante difundida no âmbito da Psicologia Social, principalmente quando se trabalha com o embasamento teórico das representações sociais (RS), uma vez que possibilita acesso aos conteúdos periféricos e latentes (Di Giacomo,1981; Le Boudec,1984; De Rosa,1988; Nóbrega \& Coutinho, 2003).

De acordo com Nóbrega e Coutinho (2003), essa técnica projetiva possibilita acesso aos conteúdos formadores de RS sem que ocorra a filtragem da censura ou do que é desejável socialmente na sua evocação. Também é um instrumento que se apóia sobre um repertório conceitual; com isso, permite a unificação dos universos semânticos e a saliência de universos de palavras comuns face aos estímulos indutores utilizados na pesquisa.

Neste estudo, foram utilizados três estímulos indutores: estímulo 1-velhice; 2- grupos da terceira idade e 3-família, previamente definidos, tendo como pressupostos o objeto investigado, o estado atual da arte bem como os atores sociais que fazem parte da amostra (idosos participantes de grupos de convivência). É válido mencionar que, na 
presente pesquisa, devido à faixa etária pesquisada ser de 60 anos ou mais, levou-se em consideração a diminuição do tempo de raciocínio cognitivo presente no envelhecimento normal (senescência), e convencionou-se o tempo máximo de 03 (três) minutos para evocação das palavras associadas a cada estímulo indutor, perfilando algo em torno de 09 minutos para que cada participante respondesse ao teste de associação livre de palavras.

\section{Procedimentos de coleta de dados}

Inicialmente, o projeto foi enviado ao Comitê de Ética em Pesquisa com Seres Humanos do CCS (Centro de Ciências da Saúde) da UFPB, com o intuito de averiguar os parâmetros éticos, tendo como base a Resolução n 196/96 e recebendo parecer de aprovação para realização da pesquisa, uma vez que sua operacionalização, de acordo com os pareceristas, não traria nenhum dano à saúde física e/ou psíquica do participante. Posteriormente, solicitou-se a autorização das coordenações dos grupos de convivência, objetivando a realização da pesquisa, bem como dos respectivos idosos dos grupos pesquisados. É válido mencionar que não foi verificada nenhuma recusa em participar da presente pesquisa.

Para aplicação dos instrumentos, participaram dois pesquisadores, previamente treinados e qualificados. Nessa etapa, inicialmente, houve apresentação dos pesquisadores aos grupos de idosos, quando se explicitaram os objetivos da pesquisa e, posteriormente, iniciou-se a aplicação dos instrumentos em situação coletiva e de forma individual.

Antes da aplicação dos três estímulos já mencionados, foi feita uma simulação utilizando um exemplo, com o intuito de familiarizar o participante com a funcionalidade do instrumento. Em seguida, foi apresentado o $1^{\circ}$ estímulo indutor, seguindo-se a questão, "o que Ihe vem à mente (cabeça) quando digo a palavra velhice?" Fale as primeiras palavras que, para o Sr (a), lembram a velhice. O mesmo procedimento foi utilizado nos outros dois estímulos (2 - grupos da terceira idade e 3 família).

\section{Análise dos dados}

Os dados coletados foram processados pelo software Tri-Deux-Mots (Cibois, 1998) versão 2.2, que permite a visualização gráfica tanto das variáveis fixas (sexo, idade e grupos de convivência) como das variáveis de opinião, crenças, estereótipos, enfim, o conhecimento prático, enunciado pelos participantes frente aos estímulos indutores e analisados através da Análise Fatorial de Correspondência (AFC). O princípio básico da AFC consiste em destacar eixos que explicam as modalidades de respostas, mostrando estruturas constituídas de elementos do campo representacional, ou seja, os conteúdos apreendidos nos discursos dos idosos frente aos estímulos indutores.

\section{Resultados e discussão}

Os resultados coletados por meio do teste de associação livre de palavras, enquanto instrumento de apreensão de significados do conhecimento prático, possibilitaram, com as variáveis fixas, a emersão de campos semânticos sobre a velhice, grupos da terceira idade e família, conforme pode ser observado no plano fatorial, através dos dois fatores nele contemplados (F1 e F2). 


\section{F1}

\begin{tabular}{|c|c|}
\hline $\begin{array}{l}\text { triste1 } \\
\qquad \text { apoio2 }\end{array}$ & participação2 \\
\hline $\begin{array}{cc}\text { 66-70 } & \text { FEMININC } \\
\begin{array}{c}\text { natural1/solidariedade2 } \\
\text { participação1 }\end{array} & \\
\text { alegria3/amigos1 } & \\
\text { alegria2 } & \text { feliz3 } \\
\text { discriminação1 } & \text { amigos } \\
\text { genro3 discriminação2 } & \\
\text { importante2 saúde1 } & \\
\text { abandono3/JUVENTUDE PRATEADA }\end{array}$ & $\begin{array}{lr} & \text { morte1 } \\
\text { não gosta1 } & \\
& \text { tudo3 }\end{array}$ \\
\hline $\begin{array}{r}\text { compreensão2 } \\
\text { solidão2 }\end{array}$ & 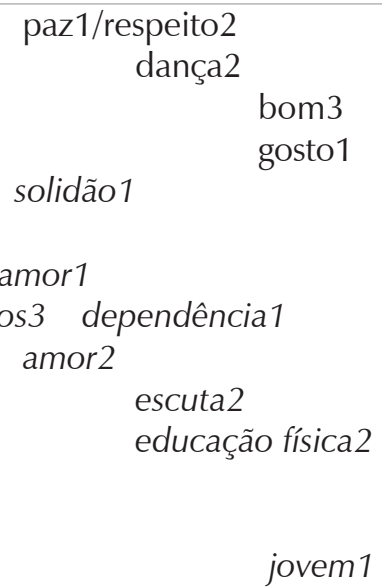 \\
\hline
\end{tabular}

Figura 1 - Análise fatorial de correspondência das representações sociais da velhice

Legenda:

$\mathrm{F} 1($ eixo negativo $)=$ negrito, horizontal

F2 (eixo positivo) $=$ itálico, vertical

\section{Estímulos Indutores}

1 -velhice

2-grupos da $3^{a}$ idade

3 - família

\section{Variáveis fixas}

\section{Sexo}

1 - Masculino

2 - Feminino
Grupos de convivência

1 - Juventude Prateada

2 - Renascer
Faixa etária

1 - 60-65 anos

$2-66-70$ anos

$3-\geq 71$ anos 
Os dados apresentados na Figura 1 correspondem às representações sociais da velhice, grupos da terceira idade e família sob a ótica dos atores sociais desta pesquisa (idosos que participam de grupos de convivência do Juventude Prateada e do Renascer), que se encontram interligadas nos dois fatores, F1 e F2.

O Fator 1 (F1) na linha horizontal, em negrito, é o de maior poder explicativo, com $45 \%$ da variância total das respostas. O fator 2 (F2), na linha vertical, em itálico, possui $24 \%$ da variância total das respostas. Na totalidade, os dois fatores têm poder explicativo de $79 \%$ de significância, possuindo, portanto, parâmetros estatísticos com consistência interna e fidedignidade, tendo em vista pesquisas realizadas no âmbito das RS (Nóbrega \& Coutinho, 2003; Araújo, 2004). Na parte horizontal superior da Figura 1, encontra-se o campo semântico das RS da velhice (estímulo 1), elaborado pelos idosos do grupo de convivência Juventude Prateada. Verificam-se as palavras em negrito com terminação 1, que se referem à representação social da velhice, apreendida entre os idosos como a fase do desenvolvimento humano marcada pela 'discriminação' e pela busca da 'saúde', tendo em vista que o surgimento de patologias nessa faixa etária, segundo eles, encontra-se mais presente do que em qualquer outra etapa da vida; eles associam também a velhice à 'morte'. Essas representações coadunam-se com o paradigma dominante em nossa cultura, que representa a velhice de forma negativa, sendo, em geral, alvo de preconceitos e discriminação.

De forma a complementar as representações do velho na sociedade contemporânea, Debert (1999) menciona que, devido às transformações do envelhecimento em problema social, postula-se uma nova denominação, tendo como pano de fundo o eufemismo, designando essa faixa etária de "terceira idade". Assim, as formas de pressão repercutem em maneiras de expressão, posto que não se trata mais de apenas resolver as dificuldades econômicas dos idosos, mas de proporcionar cuidados socioculturais e psicológicos, contribuindo para uma representação positiva da velhice.

Neri (1993), por sua vez, ressalta que o desconhecimento do que significa ser velho induz a práticas com foco ideológico, que contribuem para a manutenção e a propagação de mitos, estereótipos negativos e preconceitos acerca da velhice. Provavelmente, as atitudes preconceituosas e a auto-imagem negativa da velhice verificada entre os idosos pesquisados são devidas aos construtos psicossociais e ideológicos a priori mencionados que permeiam as relações interpessoais e afetivas presentes na atualidade.

Esse grupo enfatizou ainda que, na senescência, faz-se necessária a participação nos grupos da terceira idade, que correspondem às palavras na parte horizontal do lado superior da figura em negrito com terminação 2, uma vez que esses espaços de relações interpessoais possibilitam construir novos amigos, propiciam momentos de 'alegria', que é algo relevante e 'importante' nessa fase da vida. No entanto, denota-se uma 'discriminação' intragrupo, possivelmente devido às diferenças peculiares a esse grupo, Juventude Prateada, no âmbito socioeconômico e cultural.

No que concerne à representação da família (as palavras em negrito com terminação 3, na parte superior horizontal da figura 1) os idosos desse grupo se queixam de atitudes por parte de alguns familiares, que, apesar de conviver geralmente no mesmo espaço físico, transmitem um sentimento de 'abandono' e desrespeito, uma vez que os idosos não são consultados nas decisões familiares. No entanto, para eles, é a família um lugar de 
'alegria' e bem-estar na velhice. Fato curioso diz respeito ao destaque dado ao papel dos 'genros', que desempenham o apoio psicossocial e afetivo, na maioria das vezes, nas relações familiares para com os idosos desse grupo.

A partir dos dados a priori apresentados, pode-se inferir que os idosos do grupo Juventude Prateada representaram a velhice como busca da saúde, e denota-se que essa é uma prática entre os idosos que comumente se queixam de problemas relacionados à saúde, sendo, por diversas vezes, associada ao binômio velhice-doença. Alguns estudos realizados sobre representações sociais da velhice corroboram esses resultados, como, por exemplo, os de Santos, 1994; 1998; Junqueira, 1997; Teixeira, 1999, 2001; Costa, 2001; Araújo, 2001, em que os resultados de suas pesquisas apontaram, por parte dos idosos, uma auto-imagem negativa. É válido mencionar que o aparecimento de doenças não é algo intrínseco à velhice; no entanto, devido ao envelhecimento fisiológico, ao componente genético e ao estilo de vida, podem surgir patologias crônicas e degenerativas (Neri, 2004).

Pode-se verificar ainda, no Fator 1, na parte horizontal inferior em negrito, as representações compartilhadas pelos idosos do grupo Renascer, que definiram a velhice, nas palavras em negrito com terminação 1, como um momento de 'paz' e que 'gostam' dessa fase da vida. Quanto ao Grupo da Terceira Idade (palavras em negrito com terminação 2) os idosos do Renascer apontaram o 'respeito', que se faz presente nesses espaços de convivência, o que facilita as relações de amizade intragrupo. É válido mencionar a valorização que esses idosos deram às atividades sócio-recreativas, com destaque para a 'dança' devido à sua importância em momentos de lazer e recordações de músicas que marcaram fases da vida desses atores sociais. No que diz respeito à família (palavras em negrito com terminação 3), esses idosos mencionaram que o apoio familiar é 'bom', no sentido de possibilitar melhores formas de enfrentamento da velhice.

Assim, a rede de suporte ao idoso elaborada e desenvolvida pela família precisa ser eficaz ao que se propõe em termos de assistência às necessidades dos seus membros. É fundamental que a família repense o seu papel e se reorganize, levando-se em consideração as necessidades advindas da presença do idoso no convívio familiar (Vieira, 2004).

No Fator 2, na parte vertical, em itálico, denota-se o campo semântico elaborado por ambos os grupos de idosos, que compreende a faixa etária de 60 a 65 anos, que representa a velhice (palavras em itálico com terminação 1) como a fase do desenvolvimento em que se faz presente o 'amor' e na qual se possui o mesmo vigor físico e psicológico de quando se era 'jovem'. De forma antagônica, a velhice também é marcada pela 'dependência' e 'solidão'. Infere-se que tais representações se devam ao fato de a maioria desses idosos possuir independência financeira que lhes possibilita viverem sozinhos; no entanto, a falta de autonomia prejudica as suas atividades da vida diária.

A autonomia na velhice é uma questão que comumente faz com que seja construída uma representação de que a pessoa idosa não pode desempenhar suas tarefas e seu papel na sociedade, sendo essa fundamental para a manutenção da qualidade de vida e enfrentamento da velhice (Vieira, 2004).

No que concerne aos Grupos da Terceira Idade (palavras em itálico com terminação 2), os idosos os objetivaram como espaços que permitem a 'escuta', uma vez que, na maioria dos ambientes familiares, não é permitida a sua participação nas decisões. 
Os dados anteriormente apresentados chamam a atenção, pois a representação desses grupos de convivência como espaço de escuta só vem reforçar a negação da participação de diálogos no seio familiar para com os idosos, levando-os a viverem sentimentos de desvalorização, isolamento, depressão e auto-imagem negativa, uma vez que a comunicação e o afeto no contexto familiar são importantes para a saúde física e mental dos indivíduos (Coutinho, Gontiès, Araújo \& Sá, 2003; Araújo \& Carvalho, 2004). Esses idosos ainda enfatizaram as atividades de 'educação física' desenvolvidas nos grupos de convivência como fundamentais para um envelhecimento físico saudável. Mencionaram que há muito 'amor' entre os participantes, de modo que isso contribui para a coesão e identificação grupal, o que minimiza o sentimento de 'solidão' tão presente nessa fase do desenvolvimento humano.

No que tange à família (palavras na parte vertical da Figura 1, em itálico, com terminação 3), os idosos de 60-65 anos apontaram que os 'netos' são necessários e importantes no que diz respeito à construção familiar bem como às relações intergeracionais, e apontam também os 'cuidados' como uma condição sine qua non nas relações entre pessoas na vida cotidiana. Percebe-se, na parte esquerda em itálico, o Fator 2, que os participantes na faixa etária de 66 a 70 anos elaboraram sobre suas representações da velhice (palavras na parte vertical superior da Figura 1, em itálico, com terminação 1). Observam-se representações antagônicas; por um lado, a velhice é considerada um período para se fazer 'amigos' e para 'participação' em diversas atividades devido à liberdade que lhe é pertinente (ausência de maiores atividades), considerando o cumprimento da constituição familiar e profissional; por outro, a velhice é considerada como um período que não é bom, de que 'não gosta', devido às diversas limitações, sobretudo as relacionadas ao envelhecimento físico.

No que concerne aos grupos da terceira idade (palavras na parte vertical à esquerda da figura 1, em itálico, com terminação 2) os idosos que compreendem a faixa etária de 66 a 70 anos , afirmaram que essa rede de 'apoio' social dos 'amigos' é fundamental para uma velhice bem-sucedida. Quanto à família (palavras na parte vertical superior da figura 1, em itálico, com terminação 3), vale salientar que é 'tudo' para eles, e que possibilita momentos 'felizes', mesmo ocorrendo, conforme já mencionado, a pouca dedicação e prioridade dispensada aos mesmos.

Percebe-se ainda, no Fator 2, (parte superior da figura em itálico) que o grupo do sexo feminino teve maior contribuição. A velhice (palavras na parte vertical direita da Figura 1, em itálico, com terminação 1) foi definida por elas como um processo 'natural', apesar de destacarem momentos de 'tristeza' inerente a esse período da vida. No que tange aos grupos da terceira idade (palavras na parte vertical direita da Figura 1, em itálico, com terminação 2), as idosas os representaram como um espaço no qual elas encontram 'solidariedade', de modo que consideram de fundamental importância a 'participação' dos idosos, uma vez que esses grupos de convivência contribuem para desenvolver uma rede psicossocial e afetiva que possibilita uma prática para melhor enfrentamento da velhice.

O fato de que, neste estudo, prevaleça o sexo feminino pode ser explicado em dois direcionamentos: o primeiro é que as idosas freqüentam mais esses espaços do que os idosos; outro pode ser relativo ao fenômeno conhecido como a feminização da população idosa. Em termos de números relativos, existem cerca de 100 mulheres para apenas 82 homens idosos, devendo-se esse fato à maior expectativa de vida por parte da 
população feminina, o que é um fenômeno mundial; no Brasil, as mulheres vivem, em média, cerca de oito anos a mais que os homens (Beltrão \& Camarano, 2002).

Vale salientar que essa diferença quantitativa entre homens e mulheres idosos não é uma especificidade brasileira, e, sim, uma tendência mundial, sobretudo considerandose que a esperança de vida feminina é mais alta que a masculina em grande parte dos grupos etários mais elevados (Moreira, 2002). Provavelmente, esses dados podem explicar a participação bastante significativa da população feminina nos grupos de convivência, pois a participação masculina nesse estudo foi ínfima. Não obstante, esse fenômeno levanta outros questionamentos no que diz respeito à não presença de idosos do sexo masculino nesses espaços de convivência. É provável que isso se deva ao fato de a mulher ser mais participativa e preocupar-se com as questões relacionadas ao bem-estar de um modo geral. Há também, possivelmente, o viés cultural, posto que atividades dessa natureza, na nossa sociedade (nordestina brasileira), fazem parte do repertório social feminino.

Em síntese, é pertinente salientar que os dados apreendidos no teste de associação livre de palavras fizeram emergir um conhecimento do senso comum acerca da velhice, pautado em uma auto-imagem negativa entre os idosos, sobretudo do Grupo de Convivência Juventude Prateada. No entanto, vale destacar que a velhice foi representada, por ambos os grupos, como uma fase do desenvolvimento humano em que há maior liberdade para a realização de atividades que não foram executadas em outras fases da vida.

\section{Considerações finais}

No desenvolvimento da presente pesquisa, pretendeu-se verificar as representações sociais da velhice, grupo da terceira idade e família, elaboradas e compartilhadas por idosos que se relacionam em grupos de convivência como também compreender os diversos aspectos psicossociais relacionados a essa fase do desenvolvimento, com o fim de contribuir para um melhor conhecimento do senso comum referente ao idoso. Neste estudo, os atores sociais participavam dos grupos Juventude Prateada e Renascer.

Os dados obtidos revelaram a importância constitucional que os grupos de convivência têm para essa população, caracterizando-se como espaços por excelência, onde as práticas sociais desenvolvidas contribuem para que os idosos exerçam seu papel de cidadãos, sendo um local onde eles utilizam suas potencialidades, onde há sempre alguém que os escute, propiciando a efetivação de laços de amizade e momentos de lazer, contribuindo, também, para o restabelecimento da auto-imagem positiva, uma vez que, em geral, o contexto familiar não favorece a utilização das potencialidades dos idosos.

É válido salientar que há uma necessidade premente de manutenção dos grupos existentes e da implantação de outros, para que se possa atender a um número maior de gerontes e às comunidades que não dispõem desse serviço. Posto isso, as estatísticas demográficas apontam um crescimento progressivo e gradual da população idosa brasileira e mundial. Por isso, a demanda de participantes desses grupos irá aumentar, tendo em vista a difusão de representações positivas acerca do bem-estar propiciado nesse espaço de trocas sociais. Faz-se necessário que os diversos setores da sociedade discutam formas de oferecer uma velhice com dignidade, visto que esses são direitos assegurados na Política Nacional (Lei no 8.842 , de 04/01/1994) e no Estatuto do Idoso (Lei n 10.741, de 01/10/2003), e que merecem ser postos em prática. 
Esta pesquisa veio contribuir de forma parcimoniosa para a compreensão das representações sociais da velhice e também forneceu subsídios para que a Psicologia e a Gerontologia encontrem formas de pensar em práticas sociais de atendimento adequado e de intervenção face à velhice, no âmbito dos programas governamental e não-governamental, que favoreçam a qualidade de vida dos idosos e os auxiliem no exercício do seu papel de cidadãos e atores sociais, na sociedade contemporânea, onde o espaço privilegiado é para a juventude, a beleza e a força de trabalho produtivo.

É importante assinalar a necessidade de novas pesquisas que possam identificar, nas práticas sociais da vida cotidiana, possíveis elementos de mudança das representações e suas conseqüências positivas na construção psicossocial da velhice e do processo de envelhecimento. Salienta-se a pertinência de contemplar as representações relacionadas à inserção do idoso no contexto familiar, uma vez que o conhecimento compartilhado por esse grupo de pertença/afiliação orienta seus comportamentos e a comunicação intragrupo.

Sabe-se das limitações concernentes à presente investigação; contudo, espera-se que esta possa subsidiar políticas públicas para a velhice, uma vez que os dados empíricos deste estudo assinalaram representações sociais constituídas por uma auto-imagem negativa da velhice. Faz-se necessária a implantação de programas de atenção integral ao idoso, de modo que estas possam contribuir para uma velhice bem-sucedida e com qualidade de vida.

Ludgleydson Fernandes de Araújo -

Universidade Federal da Paraíba

Mestrando em Psicologia Social/Especialista em Gerontologia/ pesquisador do Núcleo de Pesquisa: Aspectos Psicossociais de Prevenção e Saúde Coletiva.

Maria da Penha de Lima Coutinho Universidade Federal da Paraíba. Professora com Pós-Doutorado em Psicologia pela Universidade Aberta de Lisboa-Portugal/ Programa de Pós-Graduação em Psicologia Social e coordenadora do Núcleo de Pesquisa: Aspectos Psicossociais de Prevenção e Saúde Coletiva

Virgínia Ângela Menezes de Lucena e Carvalho Universidade Federal da Paraíba.

Professora com Pós-Doutorado em Psicologia do Envelhecimento pela Universidade de SalamancaEspanha, Programa de Pós-graduação em Serviço Social / coordenadora da Base de Investigação Multidisciplinar em Desenvolvimento Adulto e Envelhecimento Humano.

Rua Antônio Leopoldo Batista, 172, Apto 306. Ed. Ibirapuera. Bairro: Bancários CEP: 58051-110 João Pessoa-PB Tel: (83) 216 7006/7675

E-mail: ludgleydson@yahoo.com.br 
ARAÚJO, L. F. Velhice e Instituições Geriátricas: um Estudo das Representações Sociais. Monografia de Especialização em Gerontologia. Universidade Federal da Paraíba, João Pessoa$\mathrm{PB}, 2004$.

ARAÚJO, L. F. ; CARVALHO, V. A M. Velhices: Estudo Comparativo das Representações Sociais entre Idosos de Grupos de Convivências. Textos sobre Envelhecimento, v. 1, n. 6, 2004, pp. 57-75.

ARAÚJO, L. F. ; CARVALHO, V. A. M. L. E. Aspectos SócioHistóricos e Psicológicos da Velhice. Mneme, UFRN, v. 06, n. DEZ-JAN, p. 01-12, 2005.

ARAÚJO, T. L. Velhice Feminina no Asilo: do Imaginário ao Real. Tese de Doutorado em Enfermagem. Universidade Federal do Ceará, Fortaleza-CE, 2001.

BeltrÃO, K. I.; CAMARANO, A. A. A Dinâmica Populacional Brasileira e a Previdência Social: uma Descrição com Ênfase nos Idosos. 2002. Referência obtida via base de dados Biblio: IPEA, Disponível na internet: http://www.prodepa.gov.br/sespa/ variedades_textos_din.htm (Consultado em 21/01/2002).

BERQUÓ, E. Considerações sobre o Envelhecimento da População no Brasil. In Neri, A. L.; Debert, G. G. (orgs.). Velhice e Sociedade. Campinas-SP: Papirus, 1998, pp.11-40.

CIBOIS, P. L'Analyse Factorielle. Paris: PUF, Collecion "Que saisje?", 1998

COSTA, F. G. Representação Social da Velhice em Idosos Participantes de Instituição para Terceira Idade. 2001. Dissertação de Mestrado em Psicologia). Universidade Católica de Goiás, Goiânia-GO, 2001.

COSTA, F. G; CAMPOS, P. H. F. Práticas Institucionais e Representações da Exclusão na Terceira Idade. In Campos, P. H. F. ; Loureiro, M. C. S. (orgs.). Representações Sociais e Práticas Educativas. Goiânia-GO: EdUCG, 2003, pp. 187-207.

COUTINHO, M. P.L. Depressão Infantil: uma Abordagem Psicossocial. João Pessoa-PB, EdUFPB, 2001.

COUTINHO, M. P. L ; GONTIÈS, B.; ARAÚJO, L. F.; SÁ, R. C. N Depressão: um Sofrimento sem Fronteira: um Estudo entre Idosos e Crianças. Psico-USF, São Paulo, v. 2, n. 13, 2003, pp. 182-190.

DEBERT, G. G. A Reinvenção da Velhice. São Paulo-SP:FAPESP, 1999.

DE ROSA, A S. Sur I'Usage des Associations Libres dans I'Etude des Représentations Sociales de la Maladie Mentale. Connexions,51, Rome:Université de Rome, 1988.

DI GIACOMO, J. P. Aspects Méthodologiques de l'Analyse des Répresentations Sociales. Cahiers de Psychologie Cognitive, v. 1, n. 1, 1981, pp. 397-422.

DOISE, W. Les Représentations Sociales. In Ghiglione, R.; Bonnet, C.; Richard, J. F.(eds.). Traité de Psychologie Cognitive. 1990, pp. 190-198.

SENADO FEDERAL. Estatuto do Idoso- Lei n ${ }^{\circ} 10.741$, de 01 de outubro de 2003. Brasília-DF, 2003.

INSTITUTO BRASILEIRO DE GEOGRAFIA E ESTATÍSTICA. Relatório do Perfil dos Idosos Responsáveis pelos Domicílios no Brasil. Rio de Janeiro, 2002.

JODELET, D. Representações Sociais: Fenômeno, Conceito e Teoria. Paris: Presses Universitares de France, 1989.
JODELET, D. As Representações Sociais. Rio de Janeiro: EdUERJ, 2001.

JUNQUEIRA, E. D. S. A Representação Social da Velhice em uma Universidade Aberta à Terceira Idade. 1997. Dissertação de Mestrado em Fonoaudiologia). Pontifícia Universidade Católica PUC, SãoPaulo-SP,1997.

LE BOUDEC, G. Contribuition à la Méthodologie d'Étude des Représentations Sociales. Cahiers de Psycologie Cognitive, v. 4, 1984 , pp. $245-272$

MINISTÉRIO DE JUSTIÇA - SECRETARIA NACIONAL DOS DIREITOS HUMANOS. Política Nacional do Idoso - Programa Nacional de Direitos Humanos. Brasília - DF, 1994.

MOREIRA, M. DE M. Mudanças Estruturais na Distribuição Etária Brasileira: 1950-2050. 2002. Referência obtida via base de dados do IPEA. Disponível na internet. http://www.fundaj.gov.br/tpd/ 117a.html (Consultado em 12/04/2002).

MOSCOVICI, S. A Representação Social da Psicanálise. Rio de Janeiro: Zahar, 1978.

MOSCOVICl, S Psycologie Sociale. Paris:Press Universitaire de France-PUF, 1984.

MOSCOVICl, S Rèpresentations Sociales. In Doise, W.; Palmonari, A. (eds.). L'Étude des Répresentations Sociales. Neuchâtel:Delachaux Niestlé, 1988, pp. 90-109.

MOSCOVICl, S. Representações Sociais: Investigações em Psicologia Social. Petrópolis-RJ:Vozes, 2003.

NERI, A. L. Qualidade de Vida e Idade Madura. Campinas: Papirus, 1993.

NERI, A L. Envelhecer com Dignidade. Jornal da UNICAMP, v. 18 , n. 247, 2004, p.12.

NERI, A. L. Teorias Psicológicas do Envelhecimento. In Freitas, E. V.; Cols. (orgs.) Tratado de Geriatria e Gerontologia. Rio de JaneiroRJ: Guanabara Koogan, 2002, pp. 32-45.

NÓBREGA, S.M \& COUTINHO, M. P. L. O Teste de Associação Livre de Palavras. In Coutinho, M. P. L.; Cols. (orgs.). Representações Sociais: Abordagem Interdisciplinar. João Pessoa: EdUFPB, 2003, pp. 67-77.

PESQUISA NACIONAL POR AMOSTRA DE DOMICÍLIOS - IBGE. Rio de Janeiro:RJ, CD-ROM, 2003.

SANTOS, M. F. S. Velhice: uma Questão Psicossocial. Temas de Psicologia, v. 2, 1994, pp. 123-131.

SANTOS, M. F. S. A Velhice na Zona Rural. Representação Social e Identidade. In Nascimento-Shulze, C. (org.). Novas Contribuições para Teorização e Pesquisa em Representações Sociais. Coletâneas ANPEPP, v. 1, n. 10, 1998, pp. 59-83.

TEIXEIRA, M. C. T. V. Velhice: Perdas ou Ganhos? Dissertação de Mestrado em Psicologia Social. Universidade Federal de Santa Catarina, Florianópolis-SC, 1999.

TEIXEIRA, M. C. T. V. Representações Sociais sobre a Saúdedoença na Velhice: um Diagnóstico Psicossocial na Rede Básica de Saúde. Tese de Doutorado em Enfermagem. Universidade Federal de Santa Catarina, Florianópolis-SC, 2001.

VIEIRA, E. B. Manual de Gerontologia: um Guia Teórico-Prático para Profissionais, Cuidadores e Familiares. Rio de Janeiro: Revinter, 2004.

WAGNER, W. \& ELEJABAMETA, F. Representaciones Sociales. In Morales, F. (org). Psicología Social. Madrid: Mcgraw-Hill, 1994, pp. 815-839.
Referências 